\title{
Collaborative intervention between pharmacists and physicians on elderly patients: a randomized controlled trial
}

This article was published in the following Dove Press journal:

Therapeutics and Clinical Risk Management

\author{
Yee Wei Shim ${ }^{1,2}$ \\ Siew Siang Chua ${ }^{1,3}$ \\ Hui Chin Wong ${ }^{4}$ \\ Syireen Alwi'
}

'Department of Pharmacy, Faculty of Medicine, University of Malaya, Kuala Lumpur, Malaysia; ${ }^{2}$ Department of Pharmacy, Duchess of Kent Hospital, Sandakan, Sabah, Malaysia; ${ }^{3}$ School of Pharmacy, Faculty of Health and Medical Sciences, Taylor's University, Subang Jaya, Selangor, Malaysia; ${ }^{4}$ Department of Medicine, Tengku Ampuan Rahimah Hospital, Klang, Selangor, Malaysia
Correspondence: Syireen Alwi Department of Pharmacy, Faculty of Medicine, University of Malaya, Kuala Lumpur 50603, Malaysia

$\mathrm{Tel}+60$ I 237I 9659

Fax +603 79674964

Email syireen@um.edu.my
Background: The elderly population is the largest consumer of medications as this age group is at high risk for developing chronic diseases. However, medication use among elderly people is complicated by an increased risk of drug-related problems. Therefore, the present study was conducted to investigate the effects of collaborative interventions between pharmacists and physicians on health-related outcomes of elderly patients.

Patients and methods: This was a randomized controlled trial (RCT) conducted on elderly outpatients who sought treatment in the Medical Outpatient Department of a public tertiary hospital in Malaysia and who were taking at least five medications. The participants were randomly allocated to the intervention and control groups. The intervention group received pharmaceutical care from a pharmacist in collaboration with physicians and was followed-up for 6 months, while the control group received usual care in the outpatient pharmacy.

Results: A total of 73 participants in the intervention group and 79 participants in the control group completed the study. Participants in the intervention group had significantly better medication adherence (median $=7.0$ vs 5.0, $U=1224.5, p<0.001, r=0.503$ ) and better Medication Appropriateness Index (MAI) score (median $=8.0$ vs 20.0, $U=749.5, p<0.001, r=0.639$ ).

Conclusion: Collaborative interventions between pharmacists and physicians improved medication adherence and MAI scores of the elderly patients. Therefore, such services should be implemented in all hospitals, especially in countries where pharmacists are still not playing a substantial role in patient care.

Trial registration: NMRR-12-958-13020.

Keywords: geriatric, medication adherence, Medication Appropriate Index, MAI, intervention

\section{Introduction}

According to the Population Reference Bureau, ${ }^{1} 8 \%$ of the world's population constitutes people aged $\geq 65$ years, which is $\sim 552$ million. The United Nations expected the older population to increase by $2 \%-2.8 \%$ annually and has estimated this figure to reach $21 \%$ of the world population by the year $2025 .^{2}$ The same trend was observed in the Asia Pacific region, where the elderly population was estimated to increase by threefold, from 420 million in year 2010 to 1.3 billion by the year $2050 .^{3}$ In Malaysia, the older population contributes to $5 \%$ of the nation's population, which is $\sim 1.3$ million people. The United Nations estimated that the number of people aged $\geq 65$ years in Malaysia would reach 2.9 million by the year $2025 .^{3}$ Factors contributing to this phenomenon included a decrease in mortality and birth rates, coupled with an increase in life expectancy. The estimated life expectancy for the world population is 69 years, 
and for Asia, it is 70 years, which is a vast increment as compared to that estimated 50 years ago, which was 49 and 46 years, respectively. ${ }^{3}$

The increase in elderly population will lead to an increase in the prevalence of diseases since this age group has a higher risk for developing chronic diseases. ${ }^{4-6}$ Consequently, the elderly population is also the largest consumer of medications and health care resources in the developed countries. ${ }^{4,7}$ This is further complicated by an increased risk of drug-related problems (DRPs) among elderly patients. These include polypharmacy, inappropriate prescribing and medication non-adherence. ${ }^{8}$ Therefore, a more comprehensive health care system is required to cater for this aging population.

Medication adherence rate among elderly patients ranged from $26 \%$ to $59 \% .{ }^{9}$ In addition, $50 \%$ of the elderly patients took their medications wrongly. ${ }^{10}$ Enhancing medication adherence has been recognized as a strategy to better manage chronic health problems effectively. ${ }^{11}$ Low medication adherence among elderly patients contributes to morbidity and mortality as well as an increase in health care cost and wastage of resources. ${ }^{12}$ Gellad et al $^{13}$ suggested that interventions to improve medication adherence among elderly patients should be prioritized.

Elderly patients visit the pharmacies regularly to refill their medications, and hence, this provides the opportunities for pharmacists to review and reconcile the patients' medications. This is especially important if the patients are receiving treatment from different medical specializations which put them at higher risk of drug duplication, drug-drug interactions and adverse drug events. ${ }^{6,14}$

Complex health care intervention has been defined as intervention that is "made up of several components, which may act both independently and inter-dependently to achieve their desired outcomes", and collaborative intervention between health care professionals is an example of such intervention. ${ }^{15}$ In this collaboration framework, pharmacists and physicians strive to improve patients' health outcomes independently, by playing their own roles, and interdependently, via discussion. This model of collaborative practice is highly recommended as everyone from different disciplines can use their own specialties and skills in improving patients' outcomes. ${ }^{16}$ In the study by Wong et al, ${ }^{17}$ various components of pharmaceutical care were delivered to elderly patients. For example, a pharmacist screened prescriptions of the elderly patients for any inappropriate medications based on the Medication Appropriateness Index (MAI) and then recommended the removal of such medications to minimize the unnecessary use of medications. In addition, patients' medication adherence and knowledge about their medications can be improved through psychosocial mechanisms such as counseling by both physicians and pharmacists. Another component of pharmaceutical care has an organizational nature, for example, the establishment of collaborative work between pharmacists and physicians will also indirectly contribute to the effectiveness of the framework. ${ }^{15}$

Several studies had been conducted to examine the involvement of pharmacists in providing pharmaceutical care to elderly patients, ${ }^{17-22}$ including studies in different settings such as in hospital pharmacies, community pharmacies and nursing homes. These studies showed that the involvement of pharmacists in geriatric care increased medication appropriateness, improved patients' medication knowledge and adherence, reduced the occurrence of DRPs, decreased mortality and reduced adverse drug reactions (ADRs). Collaboration between pharmacists and physicians had been utilized in the provision of pharmaceutical care in some studies. ${ }^{17,18}$ In Malaysia, such collaborative framework is currently not common but is gradually being implemented in most public general hospitals such as Medication Therapy and Adherence Clinic (MTAC), where pharmacists reviewed patients' medications and actively collaborated with physicians to resolve pharmaceutical care issues (PCIs). Currently, there is no published study in the literature regarding the effects of pharmaceutical care and pharmacistphysician collaboration on the elderly patients in Malaysia. The hypothesis is that the provision of pharmaceutical care to the elderly patients by pharmacists in collaboration with the physicians will have greater effects on patients' outcomes in Malaysia, where such services are still not widely practiced. Therefore, the present study was conducted to investigate the effects of such collaborative interventions on the elderly patients in Malaysia, in terms of medication adherence and medication appropriateness.

\section{Patients and methods}

This study was a randomized controlled trial (RCT) conducted in a single center, with an equal randomization ratio of $1: 1$, single-blinded and with two parallel groups. The study was approved by the Medical Research and Ethics Committee (MREC) (NMRR-12-958-13020) and registered with the National Medical Research Register (NMRR) under the Ministry of Health in Malaysia.

Any elderly patients who sought treatment in the Medical Outpatient Department (MOPD) of the Duchess of Kent Hospital in Sandakan, Sabah, Malaysia, from February 2014 to February 2015, were invited to participate in this study. Informed written consent was obtained from all participants, 
who were then followed up for 6 months from the recruitment date.

The patients aged $\geq 65$ years, who were taking at least five types of medications and who could communicate in English, Bahasa Malaysia or Mandarin were included in this study. Patients with certain medical conditions that could prevent them from effective communication (such as deaf, mute, dementia and psychiatric problems), those whose medications were supervised by their caregivers or other health care personnel and those who were participating in other studies or services, such as the Diabetes Medication Therapy Adherence Clinic (DMTAC), were excluded from this study.

Studies by Lowe et $\mathrm{al}^{23}$ and Lim et $\mathrm{al}^{20}$ used a sample size of 161 and 126, respectively. If pharmacist intervention could improve medication adherence of elderly patients by $10 \%$, with a $20 \%$ standard deviation (SD) and by using the sample calculator, OpenEpi (www.OpenEpi.com), with 95\% confidence interval and $80 \%$ power of detection, at least 160 participants would be required for the study, assuming a $20 \%$ dropout rate. The study by Spinewine et $\mathrm{al}^{24}$ found that participants in the intervention group had significant improvement in their summated MAI as compared to those in the control group with an odds ratio of 9.1 and also by using the sample calculator, OpenEpi, with $95 \%$ confidence interval and $80 \%$ power of detection, at least 92 participants would be required for the study, assuming a $20 \%$ dropout rate. Therefore, the present study required at least 160 participants.

A researcher enrolled the participants and assigned them to control or intervention groups, according to the random allocation sequence generated using a computerized random number generator, Research Randomizer (www.randomizer. org). Participants in the intervention group were provided pharmaceutical care which included medication reviews and reconciliation, counseling on the indications of their prescribed medications and how to use them. The importance of medication adherence was emphasized, and the reason(s) for non-adherence was documented and resolved accordingly. Any PCIs encountered by the participants were identified by the pharmacist and discussed with the physician concerned (if required) to resolve the issue. The collaborative framework between pharmacists and physicians in this study is illustrated in Figure 1.

Medications of participants in the intervention group were reviewed by a pharmacist prior to seeing the physician so that the pharmacist could identify and resolve any medication inappropriateness or DRPs by discussing with the physician. Any PCIs identified by the pharmacist were confirmed by another researcher in the research team: Siew Siang Chua, who is an experienced researcher and pharmacist, or by Hui Chin Wong, who is an ambulatory care clinician. Participants in the intervention group were followed up every 2 months for a 6-month period, when they came to the pharmacy for their medication refill. This duration of follow-up is similar to that in the study by Lee et al. ${ }^{25}$ Pharmaceutical care was provided every 2 months, and defaulted participants from the intervention group were contacted via telephone calls to remind them to attend their follow-ups. A participant was considered as a dropout from the study if he/she did not come for follow-up after three reminder calls.

Participants in the control group received the usual standard pharmacy service, which consisted of dispensing medications with brief instructions on the method of administration. These participants were asked to return to the pharmacy for further assessment only after 6 months. On completion of the study, all participants were given RM20 as a token of appreciation.

To prevent bias, the baseline and end point (at 6 months) outcomes were assessed by a research assistant who was blinded to the allocation of participants to the control and intervention groups. The research assistant is a registered pharmacist who has been practicing in ambulatory care for the past 10 years. Participants' medical and medication history were collected via face-to-face interviews and confirmed with that in the medical records. Interventions were delivered by a researcher who has been practicing as a pharmacist in ambulatory care for $>8$ years. A calendar was provided to all participants in the intervention group to remind them about all the appointment dates with the pharmacist, physician and when to conduct their laboratory tests.

Participants' medication appropriateness was assessed based on MAI score. ${ }^{26}$ MAI comprises 10 items which assess 10 elements of the prescribed chronic medications. Each item in MAI is weighted according to its importance in determining medication appropriateness. Indication and effectiveness of medication were rated as definitely important by all raters and thus a score of 3 would be given, while dosage, correct directions, drug-drug interactions and drug-disease interactions were rated as important and thus a score of 2 was given. Practical direction, duplication, duration and cost of treatment were rated only as moderately important and hence were given a score of 1 , while any "inappropriate" rating would be assigned a score of $0 .{ }^{27}$ Medication adherence was measured using the Malaysian Medication Adherence Scale (MALMAS) ${ }^{28}$ which is a validated instrument for assessing patients' medication adherence in Malaysia. The MALMAS 


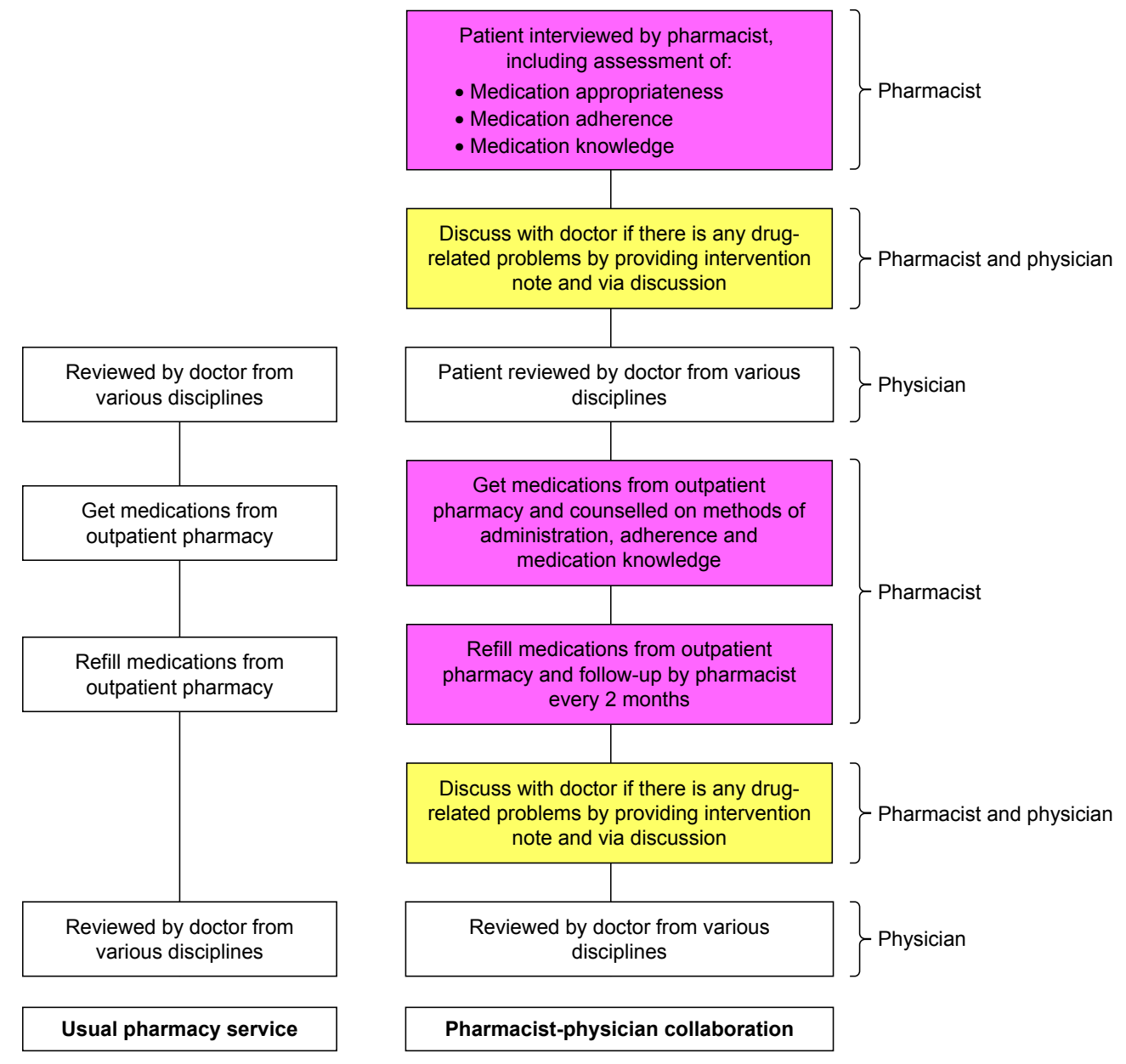

Figure I Collaboration framework between pharmacists and physicians.

consists of eight items, and the scorings are categorized as: non-adherence $\left(\right.$ scores $<6$ ) and adherence (scores 6-8). ${ }^{28}$ Knowledge of the participants concerning the use of their medications was assessed based on their understanding of the correct doses, frequencies, indications and time of administration of their medications. Participants' knowledge about their medications was measured as percentage of medications that they were able to respond correctly in terms of dose, frequency, indication and time of administration. Each of these domains was analyzed separately.

All data were analyzed using the Statistical Package for Social Sciences (SPSS) version 20 (IBM Corporation, Armonk, NY, USA). Descriptive analysis was conducted on all data, while numeric data were analyzed for mean values, SDs and medians. Association between categorical data was analyzed using the Pearson chi-square test. Differences in numeric outcomes between intervention and control groups were examined using the Mann-Whitney $U$ test for independent samples. Any $p$-value $<0.05$ was considered statistically significant.
Effect size which measures the magnitude of difference between intervention and control groups ${ }^{29}$ was reported using the formula recommended by Jin et al. ${ }^{30}$ Effect size was defined as: small $=0.1$, medium $=0.3$ and large $=0.5 .^{31}$ A generalized estimating equation (GEE) analysis was performed to confirm the effects of the collaborative interventions on participants' medication adherence and medication appropriateness based on MAI scores.

\section{Results}

A total of 160 participants were recruited over a 1-year period but only 152 participants completed the study (Figure 2). There was no significant difference between the intervention and control groups in terms of their baseline characteristics (Table 1). In this study, health problems related to the circulatory system ( $n=156,23.5 \%$ ) were the most commonly encountered problems by the elderly participants, followed by endocrine, nutritional and metabolic disorders $(n=132$, $19.9 \%)$ and those related to the genitourinary system $(\mathrm{n}=62$, 9.3\%). The participants' health problems were classified 


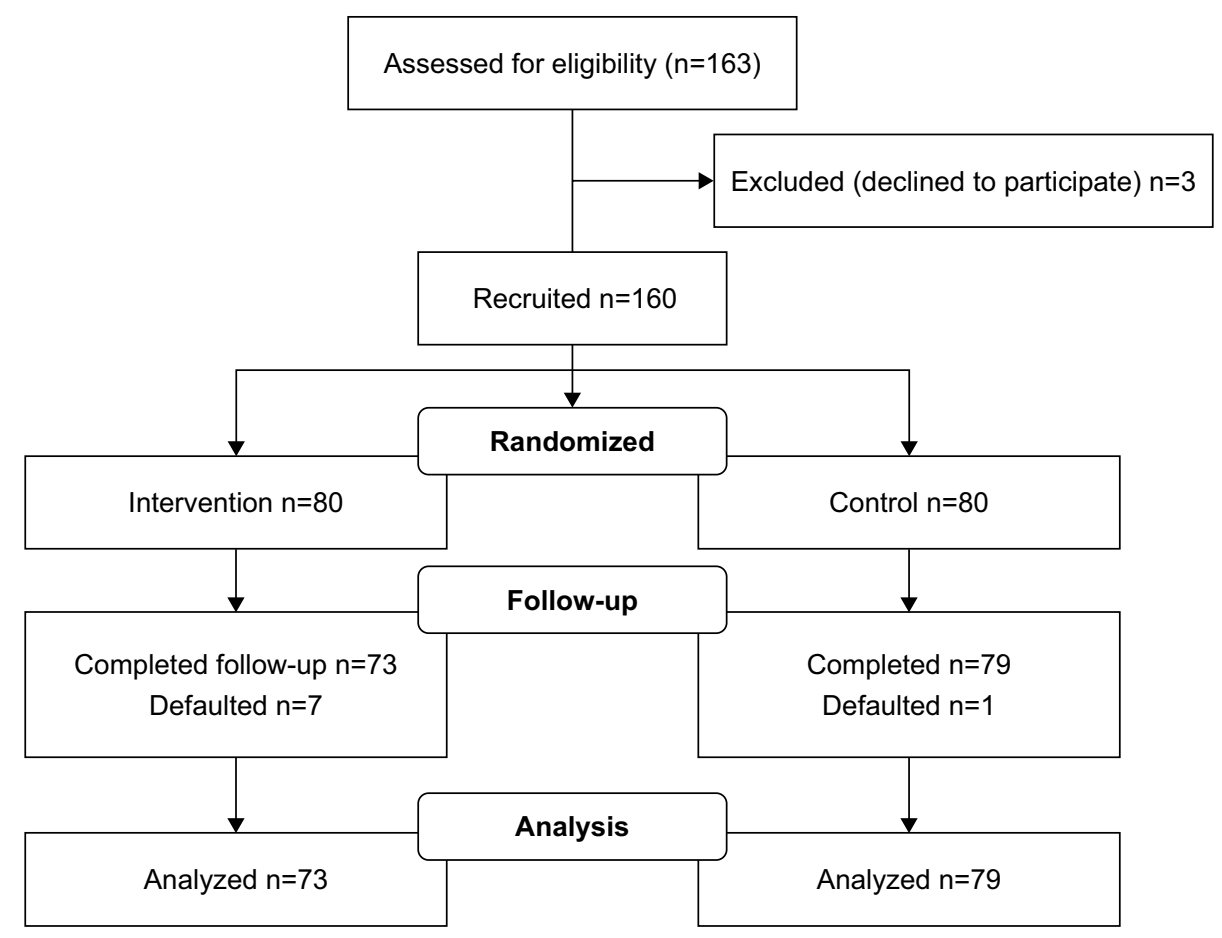

Figure 2 Flow of participants in the study.

based on the International Classification of Disease (ICD)-10 codes. ${ }^{32}$ The most frequently prescribed medications were those for the cardiovascular system $(n=155,28.2 \%)$, followed by for gastrointestinal tract and metabolism $(n=136,24.8 \%)$, and for blood and blood-forming organs $(n=113,20.6 \%)$. Medications used by the participants were classified based on the Anatomical Therapeutic Chemical (ATC) Classification System. ${ }^{33}$

There is no significant difference in terms of the baseline MAI score according to its domains except for the domain of "Duplication of drug" where the intervention group have higher mean rank as compared to the control group (mean rank 81.18 vs $72.17, p=0.039$ ). However, this would be taken into account when the changes in MAI scores from baseline to month 6 were compared between the intervention and control groups.

\section{Effects of collaborative interventions between pharmacists and physicians}

The study results showed that collaborative interventions between pharmacists and physicians had a significant effect on the elderly participants in terms of improving their medication adherence and MAI, as shown in Table 2. The effect sizes were $r=0.503$ and $r=0.639$, respectively. In addition, the intervention group showed significantly higher improvement in MAI scores for all the domains as compared to the control group (Table 3).

\section{Factors associated with medication adherence and MAI}

Nine possible factors that may be associated with medication adherence and MAI were analyzed using the GEE. It was found that the changes in medication adherence were only significantly associated with the allocated group (Table 4), while the changes in MAI were significantly associated with the allocated group, level of education and number of regular medications (Table 5).

\section{Reasons for non-adherence among elderly participants}

Out of the 160 participants, $100(65.8 \%)$ had an MALMAS score of $<6$, which means that these 100 patients were categorized as non-adherent. The reasons for non-adherence among these patients are summarized in Figure 3. Other reasons for non-adherence included those who missed their medications when they drank alcohol, family members told them to stop taking certain medications and those who took all their medications at the same time for convenience purpose.

\section{Discussion}

This study showed that collaborative interventions between pharmacists and physicians improved the MAI score and medication adherence of elderly patients. A comprehensive 
Table I Baseline characteristics of participants $(\mathrm{N}=\mid 52)$

\begin{tabular}{|c|c|c|c|c|c|}
\hline Characteristics & $\begin{array}{l}\text { Total sample, } \\
N=152\end{array}$ & $\begin{array}{l}\text { Intervention group, } \\
n=73(48.0 \%)\end{array}$ & $\begin{array}{l}\text { Control group, } \\
n=79(52.0 \%)\end{array}$ & $\begin{array}{l}\text { z value/ } \\
\text { Chi square }\end{array}$ & $p$-value \\
\hline Age (years) & & & & -0.218 & $0.827^{\mathrm{a}}$ \\
\hline Median (IQR) & $71.0(7.0)$ & $72.0(7.0)$ & $71.0(6.0)$ & & \\
\hline Range & $65.0-87.0$ & $65.0-87.0$ & $65.0-84.0$ & & \\
\hline Gender (frequency, \%) & & & & 0.005 & $0.984^{b}$ \\
\hline Male & $87(57.2)$ & $42(57.5)$ & $45(57.0)$ & & \\
\hline Female & $65(42.8)$ & $31(42.5)$ & $34(43.0)$ & & \\
\hline Ethnicity (frequency, \%) & & & & 2.400 & $0.121^{b}$ \\
\hline Chinese & $97(63.8)$ & $42(57.5)$ & $55(69.6)$ & & \\
\hline Other & $55(36.2)$ & $31(42.5)$ & $24(30.4)$ & & \\
\hline Marital status (frequency, \%) & & & & 0.734 & $0.39 I^{b}$ \\
\hline Married & $103(67.8)$ & $47(64.4)$ & $56(70.9)$ & & \\
\hline Single/divorced/widow(er) & $49(32.2)$ & $26(35.6)$ & $23(29.1)$ & & \\
\hline Educational level (frequency, \%) & & & & 1.596 & $0.450^{\mathrm{b}}$ \\
\hline No formal education & $47(30.9)$ & $19(26.0)$ & $28(35.4)$ & & \\
\hline Primary education & $61(40.1)$ & $31(42.5)$ & $30(38.0)$ & & \\
\hline Secondary education/diploma/tertiary education & $44(28.9)$ & $23(31.5)$ & $21(26.6)$ & & \\
\hline Received income per month (frequency, \%) & & & & 1.566 & $0.21 \mathrm{I}^{\mathrm{b}}$ \\
\hline No & I $32(86.8)$ & $66(90.4)$ & $66(83.5)$ & & \\
\hline Yes & $20(\mid 3.2)$ & $7(9.6)$ & $13(16.5)$ & & \\
\hline Number of clinic reviews & & & & -1.577 & $0.115^{\mathrm{a}}$ \\
\hline Median (IQR) & $2.0(1.0)$ & $1.0(1.0)$ & $2.0(1.0)$ & & \\
\hline Range & $1.0-4.0$ & $1.0-4.0$ & $1.0-4.0$ & & \\
\hline Number of comorbidities & & & & -0.634 & $0.526^{\mathrm{a}}$ \\
\hline Median (IQR) & $4.5(2.0)$ & $4.0(1.0)$ & $5.0(3.0)$ & & \\
\hline Range & $1.0-11.0$ & $1.0-9.0$ & $2.0-11.0$ & & \\
\hline Cost of medication (RM) & & & & -1.177 & $0.239^{\mathrm{a}}$ \\
\hline Median (IQR) & $65.7(96.1)$ & $58.3(84.2)$ & $75.3(97.9)$ & & \\
\hline Range & $10.8-466.9$ & $10.8-466.9$ & $11.5-252.2$ & & \\
\hline Adherence category (frequency, \%) & & & & 0.123 & $0.725^{\mathrm{b}}$ \\
\hline Non-adherence (score $<6$ ) & $100(65.8)$ & $47(64.4)$ & $53(67.1)$ & & \\
\hline Adherence (score $\geq 6$ ) & $52(34.2)$ & $26(35.6)$ & $26(32.9)$ & & \\
\hline \multicolumn{6}{|l|}{ Medication knowledge } \\
\hline Dose (\% correct) & & & & -0.176 & $0.860^{\mathrm{a}}$ \\
\hline Median (IQR) & $84.5(33.4)$ & $85.7(40.0)$ & $83.3(30.0)$ & & \\
\hline Range & $33.3-100$ & $33.3-100$ & $33.3-100$ & & \\
\hline Frequency (\% correct) & & & & -0.445 & $0.656^{\mathrm{a}}$ \\
\hline Median (IQR) & $84.5(85.7)$ & $85.7(33.3)$ & $83.3(33.3)$ & & \\
\hline Range & $14.3-100$ & $16.7-100$ & $14.3-100$ & & \\
\hline Indication (\% correct) & & & & -0.753 & $0.452^{\mathrm{a}}$ \\
\hline Median (IQR) & $66.7(56.7)$ & $71.4(66.7)$ & $66.7(54.2)$ & & \\
\hline Range & $0-100$ & $0-100$ & $0-100$ & & \\
\hline Time of administration (\% correct) & & & & -0.412 & $0.680^{\mathrm{a}}$ \\
\hline Median (IQR) & $71.4(35.7)$ & $70.0(38.8)$ & $75.0(30.2)$ & & \\
\hline Range & $14.3-100$ & $16.7-100$ & $14.3-100$ & & \\
\hline Medication Appropriateness Index & & & & -1.293 & $0.196^{\mathrm{a}}$ \\
\hline Median (IQR) & $18.0(14.0)$ & I5.0 (I3.5) & $18.0(15.0)$ & & \\
\hline Range & I.0-70.0 & $3.0-70.0$ & $1.0-48.0$ & & \\
\hline
\end{tabular}

Notes: ${ }^{a} p$-value from the Mann-Whitney $U$ test. ${ }^{b} p$-value from the Chi square test. Abbreviation: IQR, interquartile range.

medication review with emphasis on medication adherence by pharmacists is important to minimize inappropriate medication use in the elderly patients who are at higher risk of such practice and consequently ADRs. ${ }^{34}$ Referral or discussion with the physicians concerned on any PCIs encountered by the patients aided further in the improvement of the MAI score. Pharmacists should be more involved in the health care of the elderly patients. ${ }^{35}$ 
Table 2 Effects of collaborative interventions between pharmacists and physicians at 6 months $(\mathrm{N}=152)$

\begin{tabular}{|c|c|c|c|c|c|}
\hline Characteristics & $\begin{array}{l}\text { Total sample, } \\
N=152\end{array}$ & $\begin{array}{l}\text { Intervention group, } \\
n=73(48.0 \%)\end{array}$ & $\begin{array}{l}\text { Control group, } \\
n=79(52.0 \%)\end{array}$ & $\begin{array}{l}\text { z valuel } \\
\text { Chi square }\end{array}$ & $p$-value \\
\hline Adherence category (frequency, \%) & & & & $22.166^{\mathrm{a}}$ & $<0.00 I^{* *}$ \\
\hline Non-adherence $($ score $<6)$ & $76(50.0)$ & $22(30.1)$ & $54(68.4)$ & & \\
\hline Adherence (score $\geq 6$ ) & $76(50.0)$ & $51(69.9)$ & $25(31.6)$ & & \\
\hline Medication Appropriateness Index & & & & $-7.877^{\mathrm{b}}$ & $<0.00 I^{* *}$ \\
\hline Median (IQR) & II.5 (I6.0) & $8.0(9.0)$ & $20.0(16.0)$ & & \\
\hline Range & $0.0-47.0$ & $0.0-26.0$ & $3.0-47.0$ & & \\
\hline
\end{tabular}

Notes: ${ }^{\vee}$ Value from Chi square test. ${ }^{b}$ Value from Mann-Whitney $U$ test. ${ }^{* *} p<0.0$ I.

Abbreviation: IQR, interquartile range.

Table 3 Effects of collaborative interventions between pharmacists and physicians $(\mathrm{N}=152)$ on the individual domains in $\mathrm{MAl}$ at 6 months

\begin{tabular}{|c|c|c|c|c|}
\hline \multirow[t]{2}{*}{$\begin{array}{l}\text { Domains in } \\
\text { MAI }\end{array}$} & \multicolumn{2}{|c|}{$\begin{array}{l}\text { Difference in MAI scores } \\
\text { (baseline-month 6) } \\
\end{array}$} & \multirow{2}{*}{$\begin{array}{l}\text { z value } \\
\text { (Mann- } \\
\text { Whitney } \\
\text { U test) }\end{array}$} & \multirow[t]{2}{*}{$p$-value } \\
\hline & $\begin{array}{l}\text { Intervention } \\
\text { group, } n=73\end{array}$ & $\begin{array}{l}\text { Control } \\
\text { group, } \\
\mathrm{n}=79\end{array}$ & & \\
\hline \multicolumn{2}{|l|}{ Correct indication } & & -4.761 & $<0.00 I^{* *}$ \\
\hline Median (IQR) & $0(3)$ & $0(0)$ & & \\
\hline Range & -3 to 24 & -6 to 3 & & \\
\hline Mean rank & 91.22 & 62.90 & & \\
\hline \multicolumn{2}{|l|}{ Effectiveness } & & -2.063 & $0.039 *$ \\
\hline Median (IQR) & $0(0)$ & $0(0)$ & & \\
\hline Range & -3 to 9 & -6 to 3 & & \\
\hline Mean rank & 81.27 & 72.09 & & \\
\hline \multicolumn{2}{|l|}{ Correct dosage } & & -4.637 & $<0.00 I^{* *}$ \\
\hline Median (IQR) & $2(4)$ & $0(4)$ & & \\
\hline Range & -4 to 10 & -6 to 7 & & \\
\hline Mean rank & 93.25 & 61.02 & & \\
\hline \multicolumn{2}{|c|}{ Correct direction } & & -4.950 & $<0.00 I^{* *}$ \\
\hline Median (IQR) & $0(2)$ & $0(0)$ & & \\
\hline Range & -4 to 8 & -6 to 6 & & \\
\hline Mean rank & 92.41 & 61.80 & & \\
\hline \multicolumn{2}{|c|}{ Practical direction } & & -4.388 & $<0.00 I^{* *}$ \\
\hline Median (IQR) & $0(I)$ & $0(0)$ & & \\
\hline Range & -1 to 4 & -3 to 2 & & \\
\hline Mean rank & 90.46 & 63.60 & & \\
\hline \multicolumn{2}{|c|}{ Drug-drug interaction } & & -2.280 & $0.023^{*}$ \\
\hline Median (IQR) & $0(2)$ & $0(0)$ & & \\
\hline Range & -4 to 10 & -8 to 8 & & \\
\hline Mean rank & 84.06 & 69.51 & & \\
\hline \multicolumn{2}{|c|}{ Drug-disease interaction } & & -2.970 & $0.003^{* *}$ \\
\hline Median (IQR) & $0(2)$ & $0(0)$ & & \\
\hline Range & -6 to 8 & -6 to 6 & & \\
\hline Mean rank & 86.40 & 67.35 & & \\
\hline \multicolumn{2}{|c|}{ Duplication of drug } & & -2.844 & $0.004 * *$ \\
\hline Median (IQR) & $0(0)$ & $0(0)$ & & \\
\hline Range & -1 to 8 & -2 to 8 & & \\
\hline Mean rank & 83.08 & 70.42 & & \\
\hline \multicolumn{2}{|c|}{ Duration of therapy } & & -5.284 & $<0.001 * *$ \\
\hline Median (IQR) & I (I) & $0(1)$ & & \\
\hline Range & -1 to 8 & -2 to 6 & & \\
\hline Mean rank & 94.78 & 59.61 & & \\
\hline \multicolumn{2}{|c|}{ Cost of medication } & & -5.787 & $<0.00 I^{* *}$ \\
\hline Median (IQR) & I (2) & $0(I)$ & & \\
\hline Range & -1 to 4 & -5 to 3 & & \\
\hline Mean rank & 96.61 & 57.92 & & \\
\hline
\end{tabular}

Notes: $* p<0.05 ; * * p<0.01$.

Abbreviations: IQR, interquartile range; MAI, Medication Appropriateness Index.

\section{Medication adherence}

The overall baseline medication adherence among participants in this study was only $34.2 \%$. This finding is consistent with that reported in the literature which ranged from $26 \%$ to $59 \%$ and is a cause for concern as the elderly patients are the largest consumers of medications and health resources.

Collaborative interventions between pharmacists and physicians were found to increase medication adherence significantly among elderly participants. Medication adherence among participants in the intervention group was significantly higher than that of the control group (69.9 vs $31.6 \%$, with a difference of $38.3 \% ; p<0.001)$. This is also consistent with that of other studies which reported a range of $3 \%-43 \% .{ }^{9}, 12,36$ The effect size of the interventions on medication adherence was large, with $r=0.503 .{ }^{30}$ This can be interpreted as the probability of a randomly selected elderly patient from the intervention group having better medication adherence than a randomly selected elderly patient from the control group was $50.3 \% .{ }^{37}$ None of the existing studies in the literature reported an effect size of collaborative interventions on medication adherence of the elderly patients and thus no comparison can be made. The GEE analysis further confirmed that the improvement of medication adherence in the intervention group is attributed to the collaborative intervention.

The main reasons for non-adherence to medications were forgetfulness $(43.1 \%)$, to avoid side effects $(26.8 \%)$, patients felt healthy or better so thought that they did not have to continue taking the medicines $(15.0 \%)$ and patients felt that they had to take too many medicines $(15.0 \%)$. The findings of this study are similar to those described by George et al. ${ }^{12}$ The main reason of non-adherence was forgetfulness, which was unintentional, while the other reasons were mainly intentional non-adherence. Therefore, intervention by health care professionals should focus on helping the elderly patients to remember to take their medications and also to simplify their regimens, for example, linking their daily drug administration with their daily activities such as the time of their meals. Medications of the elderly patients 
Table 4 Factors associated with medication adherence using the generalized estimating equation

\begin{tabular}{|c|c|c|c|c|c|c|}
\hline \multirow[t]{2}{*}{ Variables } & \multirow[t]{2}{*}{ B } & \multirow[t]{2}{*}{ SE } & \multirow[t]{2}{*}{ 95\% Wald Cl } & \multicolumn{3}{|c|}{ Hypothesis test } \\
\hline & & & & $\begin{array}{l}\text { Wald Chi } \\
\text { square }\end{array}$ & $d f$ & $p$-value \\
\hline Intercept & 2.743 & 2.2270 & $-1.622,7.108$ & 1.517 & 1 & 0.218 \\
\hline \multicolumn{7}{|l|}{ Gender } \\
\hline Male & 0.009 & 0.2626 & $-0.506,0.523$ & 0.001 & I & 0.973 \\
\hline \multicolumn{7}{|l|}{ Female } \\
\hline \multicolumn{7}{|l|}{ Ethnicity } \\
\hline Other & -0.450 & 0.3188 & $-1.075,0.175$ & 1.992 & I & 0.158 \\
\hline \multicolumn{7}{|l|}{ Chinese } \\
\hline \multicolumn{7}{|l|}{ Marital status } \\
\hline Single/divorced/widow(er) & 0.107 & 0.3038 & $-0.488,0.702$ & 0.124 & I & 0.725 \\
\hline \multicolumn{7}{|l|}{ Married } \\
\hline \multicolumn{7}{|l|}{ Educational level } \\
\hline No formal education & 0.636 & 0.4159 & $0.179,1.45 \mid$ & 2.338 & 1 & 0.126 \\
\hline Primary education & 0.177 & 0.2197 & $0.394,0.749$ & 0.370 & I & 0.543 \\
\hline \multicolumn{7}{|c|}{ Secondary education/diploma/tertiary education } \\
\hline \multicolumn{7}{|c|}{ Received income per month } \\
\hline No & 0.447 & 0.3586 & $-1.149,0.256$ & 1.552 & 1 & 0.213 \\
\hline \multicolumn{7}{|l|}{ Yes } \\
\hline \multicolumn{7}{|c|}{ Hospitalization in previous 6 months } \\
\hline No & 0.623 & 0.3567 & $-0.076,1.322$ & 3.052 & I & $0.08 \mathrm{I}$ \\
\hline \multicolumn{7}{|l|}{ Yes } \\
\hline \multicolumn{7}{|l|}{ Group allocation } \\
\hline Intervention & 0.958 & 0.2666 & $0.436,1.480$ & 12.916 & I & $<0.00 I^{* *}$ \\
\hline \multicolumn{7}{|l|}{ Control } \\
\hline Age & -0.044 & 0.0318 & $-0.106,0.018$ & 1.915 & I & 0.166 \\
\hline Number of medications & -0.085 & 0.0492 & $-0.181,0.012$ & 2.972 & 1 & 0.085 \\
\hline
\end{tabular}

Note: $* * p<0.01$.

Abbreviations: $\mathrm{Cl}$, confidence interval; SE, standard error.

should be reviewed periodically by pharmacists to avoid non-adherence and inappropriate use of medications. Reasons for non-adherence among elderly patients are multifactorial and individualized. Therefore, it is essential to identify these reasons and provide individual solution to help these patients use their medications more effectively.

\section{MAI}

The overall baseline MAI in this study was 18 . There is a wide range of baseline MAI reported in the literature which may be due to various factors. The source of information may differ, for example, patient interviews together with review of medical records will be more comprehensive than just the review of medical records since patient's preference has to be considered in the scoring of MAI. ${ }^{26}$ The setting of the study can also affect the MAI. The present study was conducted in a tertiary hospital located in a suburban area of a developing country, whereas a majority of the studies in the literature were carried out in the developed countries with a more comprehensive health care system for the elderly population..$^{24,38-41}$ Crotty et $\mathrm{al}^{38}$ reported a baseline MAI of
6.7 among elderly patients from a nursing home, whereas Castelino et a ${ }^{14}$ reported a high baseline MAI of 18.6 among community dwelling elderly patients. This is probably due to the high number of medications taken by the elderly patients in the general community.

Collaborative interventions between pharmacists and physicians in the present study were found to improve medication appropriateness significantly among elderly patients. This finding is consistent with the existing literature studies. ${ }^{24,38-41}$ The effect size of medication appropriateness was large, with $r=0.639 .{ }^{30}$ This means that the chance for a randomly selected elderly patient from the intervention group to have a better MAI than a randomly selected elderly patient from the control group was $63.9 \%{ }^{37}$ None of the existing studies in the literature reported an effect size of collaborative intervention on medication appropriateness of elderly patients and hence comparison cannot be made. In addition, the GEE analysis showed that the allocated groups (intervention group or control group), education level and number of regular medications were significantly associated with the improvement in MAI scores. This further 
Table 5 Factors associated with Medication Appropriateness Index using the generalized estimating equation

\begin{tabular}{|c|c|c|c|c|c|c|}
\hline \multirow[t]{2}{*}{ Variables } & \multirow[t]{2}{*}{ B } & \multirow[t]{2}{*}{ SE } & \multirow[t]{2}{*}{ 95\% Wald Cl } & \multicolumn{3}{|c|}{ Hypothesis test } \\
\hline & & & & $\begin{array}{l}\text { Wald Chi } \\
\text { square }\end{array}$ & $d f$ & $p$-value \\
\hline Intercept & -5.259 & 8.9228 & $-22.747,12.230$ & 0.347 & I & 0.556 \\
\hline \multicolumn{7}{|l|}{ Gender } \\
\hline Male & -0.023 & 1.2310 & $-2.436,2.390$ & 0 & 1 & 0.985 \\
\hline \multicolumn{7}{|l|}{ Female } \\
\hline \multicolumn{7}{|l|}{ Ethnicity } \\
\hline Other & -2.144 & I.I 447 & $-4.388,0.099$ & 3.510 & 1 & 0.061 \\
\hline \multicolumn{7}{|l|}{ Chinese } \\
\hline \multicolumn{7}{|l|}{ Marital status } \\
\hline Single/divorced/widow(er) & -0.978 & 1.0920 & $-3.118,1.162$ & 0.802 & 1 & 0.370 \\
\hline \multicolumn{7}{|l|}{ Married } \\
\hline \multicolumn{7}{|l|}{ Educational level } \\
\hline No formal education & 3.445 & 1.7096 & $0.095,6.796$ & 4.062 & 1 & $0.044^{*}$ \\
\hline Primary education & 0.872 & 1.4628 & $-1.995,3.739$ & 0.356 & 1 & 0.551 \\
\hline \multicolumn{7}{|c|}{ Secondary education/diploma/tertiary education } \\
\hline \multicolumn{7}{|c|}{ Received income per month } \\
\hline No & 1.420 & 1.7184 & $-1.948,4.788$ & 0.683 & 1 & 0.409 \\
\hline \multicolumn{7}{|l|}{ Yes } \\
\hline \multicolumn{7}{|c|}{ Hospitalization in previous 6 months } \\
\hline No & 1.187 & 0.9965 & $-0.767,3.140$ & 1.418 & I & 0.234 \\
\hline \multicolumn{7}{|l|}{ Yes } \\
\hline \multicolumn{7}{|l|}{ Group allocation } \\
\hline Intervention & -5.710 & 1.1397 & $-7.943,-3.476$ & 25.097 & 1 & $<0.00 I^{* *}$ \\
\hline \multicolumn{7}{|l|}{ Control } \\
\hline Age & 0.072 & 0.1345 & $-0.192,0.335$ & 0.284 & 1 & 0.594 \\
\hline Number of medications & 2.128 & 0.2513 & $1.635,2.620$ & 71.698 & 1 & $<0.00 I^{* *}$ \\
\hline
\end{tabular}

Notes: $* p<0.05 ; * * p<0.01$.

Abbreviations: $\mathrm{Cl}$, confidence interval; SE, standard error.

confirmed the positive effect of collaboration between pharmacists and physicians on the MAI score and also showed that higher number of medications imposed a higher risk of inappropriate medications being given to the elderly patients.
GEE analysis also showed that participants with no formal education were associated with higher MAI score. This might be because the participants with no formal education were less likely to discuss their medications with their physicians

Did not want other people to notice that he/she was taking medicines

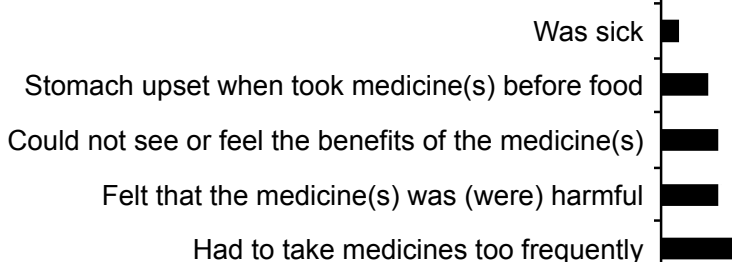

Had to take medicines too frequently

Confused about how to take

Ran out of medicines

Had too many medicines to take

Felt healthy/better, so thought that did not have to take medicines

Other

Wanted to avoid side effects

Forgot to take
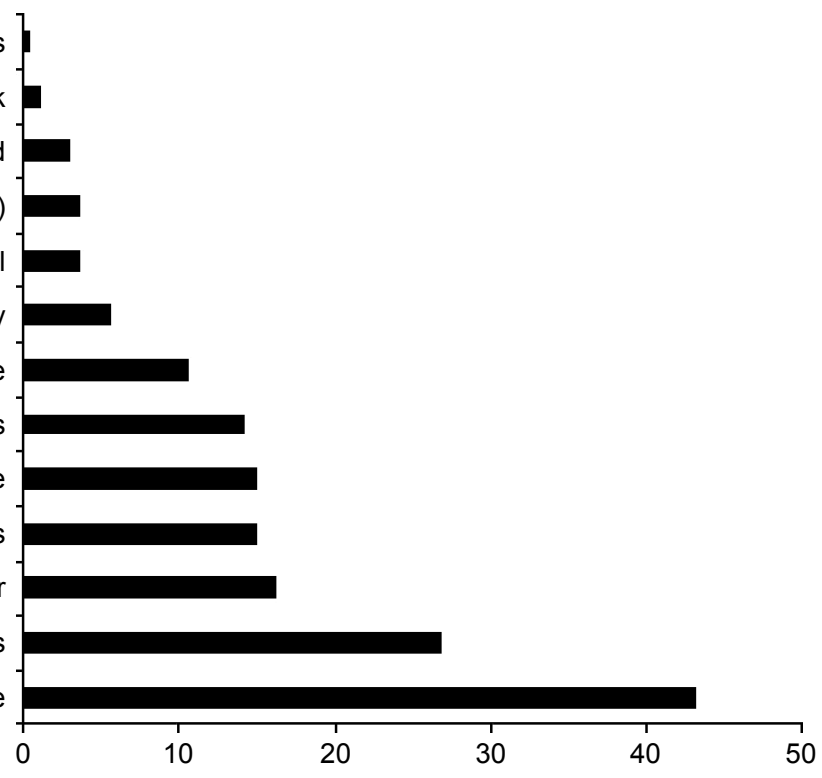

Figure 3 Reasons for non-adherence to medications (\% of participants, $\mathrm{N}=160$ ). 
or pharmacists, and hence, there was less chance of the health care professionals reconciling their medications.

\section{Study limitations}

This study recruited participants from only a single center, and hence, the results may not be generalizable to the elderly patients in other parts of Malaysia. Future work which involves multiple centers is recommended in order to obtain a better representation of the elderly patients in Malaysia. Participants were followed up for 6 months only in the present study, based on a similar study by Lee et al. ${ }^{25}$ This short study duration limited the determination of clinical outcomes such as the rate of hospitalization and mortality.

\section{Conclusion}

The present study showed that collaborative interventions between pharmacists and physicians on the elderly patients in a public hospital produced positive outcomes, in terms of medication adherence and MAI. Therefore, such services should be implemented in all health entities, especially in countries where pharmacists are still not playing an active role in patient care.

\section{Acknowledgments}

The authors thank Ms Annie Soong for helping in the data collection and all the staff of Duchess of Kent Hospital for their cooperation. The authors also like to acknowledge the University of Malaya for providing a research grant for this study (PG017-2013A). Our greatest appreciation to all the participants for their cooperation and for their willingness to spend time with us in this study. Last but not least, the authors would like to thank the Director General of Health Malaysia for his permission to publish this article.

\section{Disclosure}

The authors report no conflicts of interest in this work.

\section{References}

1. Population Reference Bureau [webpage on the Internet]. 2010 World Population Data Sheet. 2010. Available from: www.prb.org/Publications/ Datasheets/2010/2010wpds.aspx. Accessed March 31, 2012.

2. United Nations [webpage on the Internet]. World Population Aging 1950-2050. 2002. Available from: http://www.un.org/esa/population/ publications/worldageing19502050/. Accessed March 31, 2012.

3. United Nations [home page on the Internet]. World Population Prospects: The 2010 Revision. 2011. Available from: http://esa.un.org/. Accessed March 31, 2012.

4. Gallagher P, Barry P, O'Mahony D. Inappropriate prescribing in the elderly. J Clin Pharm Ther. 2007;32(2):113-121.

5. Mafauzy M. The problems and challenges of the aging population of Malaysia. Malays J Med Sci. 2000;7(1):1-3.
6. Olsson IN, Runnamo R, Engfeldt P. Medication quality and quality of life in the elderly, a cohort study. Health Qual Life Outcomes. 2011;9:95.

7. Shelton PS, Fritsch MA, Scott MA. Assessing medication appropriateness in the elderly: a review of available measures. Drugs Aging. 2000; 16(6):437-450.

8. Vinks TH, Egberts TC, de Lange TM, de Koning FH. Pharmacist-based medication review reduces potential drug-related problems in the elderly: the SMOG controlled trial. Drugs Aging. 2009;26(2):123-133.

9. van Eijken M, Tsang S, Wensing M, de Smet PA, Grol RP. Interventions to improve medication compliance in older patients living in the community: a systematic review of the literature. Drugs Aging. 2003;20(3): 229-240.

10. MacLaughlin EJ, Raehl CL, Treadway AK, Sterling TL, Zoller DP, Bond CA. Assessing medication adherence in the elderly: which tools to use in clinical practice? Drugs Aging. 2005;22(3):231-255.

11. World Health Organization (WHO). Adherence to Long-term Therapies: Evidence for Action. Geneva, Switzerland: WHO; 2003.

12. George J, Elliott RA, Stewart DC. A systematic review of interventions to improve medication taking in elderly patients prescribed multiple medications. Drugs Aging. 2008;25(4):307-324.

13. Gellad WF, Grenard JL, Marcum ZA. A systematic review of barriers to medication adherence in the elderly: looking beyond cost and regimen complexity. Am J Geriatr Pharmacother. 2011;9(1):11-23.

14. Castelino RL, Bajorek BV, Chen TF. Retrospective evaluation of home medicines review by pharmacists in older Australian patients using the medication appropriateness index. Ann Pharmacother. 2010; 44(12):1922-1929.

15. Wong IC. Randomised controlled trials (RCTs) to evaluate complex healthcare interventions - a case study. Pharm World Sci. 2004;26(5): 247-252.

16. McDonough RP, Doucette WR. Dynamics of pharmaceutical care: developing collaborative working relationships between pharmacists and physicians. J Am Pharm Assoc. 2001;41(5):682-692.

17. Wong I, Campion P, Coulton S, et al. Pharmaceutical care for elderly patients shared between community pharmacists and general practitioners: a randomised evaluation. RESPECT (Randomised Evaluation of Shared Prescribing for Elderly people in the Community over Time) [ISRCTN16932128]. BMC Health Serv Res. 2004;4(1):11.

18. Bryant LJ, Coster G, Gamble GD, McCormick RN. The General Practitioner-Pharmacist Collaboration (GPPC) study: a randomised controlled trial of clinical medication reviews in community pharmacy. Int J Pharm Pract. 2011;19(2):94-105.

19. Hanlon JT, Lindblad CI, Gray SL. Can clinical pharmacy services have a positive impact on drug-related problems and health outcomes in community-based older adults? Am J Geriatr Pharmacother. 2004; 2(1):3-13.

20. Lim WS, Low HN, Chan SP, Chen HN, Ding YY, Tan TL. Impact of a pharmacist consult clinic on a hospital-based geriatric outpatient clinic in Singapore. Ann Acad Med Singapore. 2004;33(2):220-227.

21. Tulner LR, Frankfort SV, Gijsen GJ, van Campen JP, Koks CH, Beijnen JH. Drug-drug interactions in a geriatric outpatient cohort: prevalence and relevance. Drugs Aging. 2008;25(4):343-355.

22. Wu JYF, Leung WYS, Chang S, et al. Effectiveness of telephone counselling by a pharmacist in reducing mortality in patients receiving polypharmacy: randomised controlled trial. BMJ. 2006;333(7567):522.

23. Lowe CJ, Raynor DK, Purvis J, Farrin A, Hudson J. Effects of a medicine review and education programme for older people in general practice. Br J Clin Pharmacol. 2000;50(2):172-175.

24. Spinewine A, Swine C, Dhillon S, et al. Effect of a collaborative approach on the quality of prescribing for geriatric inpatients: a randomized, controlled trial. J Am Geriatr Soc. 2007;55(5):658-665.

25. Lee JK, Grace KA, Taylor AJ. Effect of a pharmacy care program on medication adherence and persistence, blood pressure, and low-density lipoprotein cholesterol: a randomized controlled trial. JAMA. 2006; 296(21):2563-2571. 
26. Hanlon JT, Schmader KE, Samsa GP, et al. A method for assessing drug therapy appropriateness. J Clin Epidemiol. 1992;45(10):1045-1051.

27. Samsa GP, Hanlon JT, Schmader KE, et al. A summated score for the medication appropriateness index: development and assessment of clinimetric properties including content validity. J Clin Epidemiol. 1994; 47(8):891-896.

28. Chua SS, Lai PSM, Tan CH, Chan SP, Chung WW, Morisky DE. The development and validation of the Malaysian Medication Adherence Scale (MALMAS) on patients with type 2 diabetes in Malaysia. Int $J$ Pharm Pharm Sci. 2013;5(3):790-794.

29. Sullivan GM, Feinn R. Using effect size - or why the p value is not enough. J Grad Med Educ. 2012;4(3):279-282.

30. Jin H, Kim Y, Rhie SJ. Factors affecting medication adherence in elderly people. Patient Prefer Adherence. 2016;10:2117-2125.

31. Cohen J. A power primer. Psychol Bull. 1992;112(1):155-159.

32. World Health Organisation (WHO) [webpage on the Internet]. ICD-10 Classifications of Mental and Behavioural Disorder: Clinical Descriptions and Diagnostic Guidelines. 1992. Available from: http:// www.who.int/classifications/icd/en/. Accessed January 3, 2016.

33. World Health Organisation (WHO) [webpage on the Internet]. ATC/ DDD Index 2016. 2016. Available from: http://www.whocc.no/ atc_ddd_index/. Accessed January 3, 2016.

34. Barry PJ, O’Keefe N, O’Connor KA, O’Mahony D. Inappropriate prescribing in the elderly: a comparison of the Beers criteria and the improved prescribing in the elderly tool (IPET) in acutely ill elderly hospitalized patients. J Clin Pharm Ther. 2006;31(6):617-626.
35. Kallio S, Kumpusalo-Vauhkonen A, Jarvensivu T, Mantyla A, Pohjanoksa-Mantyla M, Airaksinen M. Towards interprofessional networking in medication management of the aged: current challenges and potential solutions in Finland. Scand J Prim Health Care. 2016; 34(4):368-376.

36. Schlenk EA, Bernardo LM, Organist LA, Klem ML, Engberg S. Optimizing medication adherence in older patients: a systematic review. J Clin Outcomes Manag. 2008;15(12):595-606.

37. Lakens D. Calculating and reporting effect sizes to facilitate cumulative science: a practical primer for t-tests and ANOVAs. Front Psychol. 2013;4:863.

38. Crotty M, Halbert J, Rowett D, et al. An outreach geriatric medication advisory service in residential aged care: a randomised controlled trial of case conferencing. Age Ageing. 2004;33(6):612-617.

39. Crotty M, Rowett D, Spurling L, Giles LC, Phillips PA. Does the addition of a pharmacist transition coordinator improve evidence-based medication management and health outcomes in older adults moving from the hospital to a long-term care facility? Results of a randomized, controlled trial. Am J Geriatr Pharmacother. 2004;2(4):257-264.

40. Hanlon JT, Weinberger M, Samsa GP, et al. A randomized, controlled trial of a clinical pharmacist intervention to improve inappropriate prescribing in elderly outpatients with polypharmacy. Am J Med. 1996; 100(4):428-437.

41. Schmader KE, Hanlon JT, Pieper CF, et al. Effects of geriatric evaluation and management on adverse drug reactions and suboptimal prescribing in the frail elderly. Am J Med. 2004;116(6):394-401.
Therapeutics and Clinical Risk Management

\section{Publish your work in this journal}

Therapeutics and Clinical Risk Management is an international, peerreviewed journal of clinical therapeutics and risk management, focusing on concise rapid reporting of clinical studies in all therapeutic areas, outcomes, safety, and programs for the effective, safe, and sustained use of medicines. This journal is indexed on PubMed Central, CAS,

\section{Dovepress}

EMBase, Scopus and the Elsevier Bibliographic databases. The manuscript management system is completely online and includes a very quick and fair peer-review system, which is all easy to use. Visit http://www.dovepress.com/testimonials.php to read real quotes from published authors.

Submit your manuscript here: http://www.dovepress.com/therapeutics-and-clinical-risk-management-journal 